\title{
Compressive Properties of Granular Foams of Adhesively Bonded Steel Hollow Sphere Blocks
}

\author{
Stylianos Yiatros ${ }^{\mathrm{a}, \mathrm{b}, *}$, Orestes Marangos ${ }^{\mathrm{a}}$, Renos A. Votsis $^{\mathrm{a}}$, Feargal P. \\ Brennan ${ }^{\mathrm{b}, \mathrm{c}}$ \\ ${ }^{a}$ Department of Civil Engineering 8 Geomatics, Cyprus University of Technology 3036, \\ Limassol, Cyprus. \\ ${ }^{b}$ Centre of Offshore Renewable Energy, Cranfield University, MK43 OAL, UK. \\ ${ }^{c}$ James Blyth Chair, Naval Architecture, Ocean and Marine Engineering, Strathclyde \\ University, G1 $1 X Q$, UK.
}

\begin{abstract}
Steel hollow spheres adhesively bonded together as a granular composite metal foam, is a special type of porous metal that aims to combine low weight, with ductility and energy absorption. Hollow spheres comprising steel foam shells were coated with a thermally activated epoxy in order to form different specimen geometries upon moulding and curing. The collapse propagation and energy absorption of steel hollow sphere blocks, comprising spheres of different sizes, was investigated experimentally, quantifying quasi-elastic and nonlinear properties of the steel hollow sphere assemblies in compression and comparing them with analytical and semi-empirical rules based on porous metal density and sphere packing. The results identify the initiation and nature of damage and highlight the merits of the material in absorbing high compressive deformations without significant loss of integrity.
\end{abstract}

Keywords: metal foams, steel hollow sphere assemblies, compression testing, crush band propagation

\footnotetext{
* Corresponding author

Email address: stylianos.yiatros@cut.ac.cy (Stylianos Yiatros)
} 


\section{Introduction}

Metal foams enjoy many of the mechanical characteristics of metallic structural materials, such as high stiffness and plasticity, with the advantage of low weight due to their porous microstructure. For this reason, significant effort has been put forth during the past 20 years in their manufacture, characterization and understanding of their mechanical behaviour [1]. Manufacturing techniques for metal foams are devoted to tailoring the foam microstructure in order to suit design parameters while considering economic production. A widely used manufacturing method is powder metallurgy, where alloy powder is mixed and then compressed with a foaming agent (for example titanium hydride) to form a precursor. The solid mixture is then foamed to a specified density or volume and cooled in stages. Other manufacturing processes include syntactic metal foams by metal powder injection moulding and casting for open-cell foams using organic placeholders, as described in Banhart [2]. Open cell metal foams are less stiff, have higher porosity and see applications in process engineering for heat exchangers and as hosts of catalytic reactions [3].

The need to produce more uniform porosity foams from iron-based metals with higher melting points led to the development of the metal (foam) sphere production techniques via powder metallurgy [4]. The manufacturing procedure begins with polymeric (styrofoam) spheres, coated with steel powder, known as 'green spheres' (see Figure 1(a)). These are then heat treated for the metal to melt and the polymer to sublime through the pores of the newly formed hollow shell, which is the cooled down to harden [5]. Assemblies of hollow spheres can be produced by sintering them together (Figure 1(b)), leading to a syntactic structure of very high porosity, joined together with a resin which leads to a low-weight composite structure (Figure 1(c)) or pouring molten aluminium leading to a denser porous metal [6]. The behaviour of sintered hollow sphere metal foams under compression has been studied by several authors [7, 8]. However, these studies highlight shortcomings in controlling the tension response of sintered steel hollow sphere specimens and their machining [9], suggesting that 
alternative bonding methods should be investigated. Sintered spheres form narrow, brittle connecting bridges, known as 'micro-struts' or 'necks' between the sphere particles. An improvement without compromising the low weight of the assembly is proposed where the spheres are coated with a thermosetting adhesive, forming wider, more elastic necks between adjoining spheres after curing. The work presented herein investigates the compressive properties of steel hollow sphere foam assemblies where the bonding between the spheres is effected through a thermosetting polymeric adhesion. Cubic specimens of assemblies from spheres of two different diameters were prepared and tested in compression, while results were recorded through crosshead displacement and load as well as with a Digital Image Correlation (DIC) system.

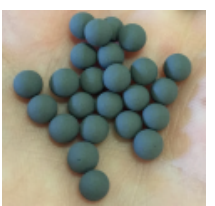

(a)

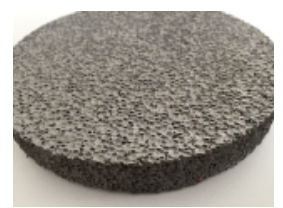

(b)

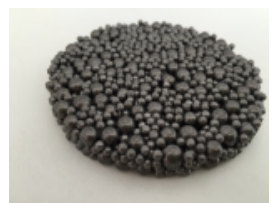

(c)

Figure 1: (a) 'Green' spheres comprising styrofoam units coated by steel powder, (b) a sintered assembly of steel hollow spheres, (c) an assembly of steel hollow spheres of different sizes bonded together by an adhesive.

\section{Specimen preparation and physical properties}

\subsection{Sphere properties}

Cubic specimens with a steel hollow spheres of two different sizes were prepared, labeled for subsequent discussion as SHS2 and SHS4. Their physical properties, as provided by the manufacturer (Hollomet GmbH) are summarized in Table 1. The spheres were pre-coated with a thermosetting adhesive, Araldite AT1-1, which requires a raised temperature to be activated.

The individual spheres were composed of a $\mathrm{FeCuP}$ alloy with carbon content $0.14 \%$ and $0.17 \%$. The main distinction between the two types, is their diameter 


\begin{tabular}{|c|c|c|c|c|c|c|c|}
\hline $\begin{array}{c}\text { Sphere/ } \\
\text { Assembly } \\
\text { type }\end{array}$ & $\begin{array}{c}\text { C- } \\
\text { content } \\
(\%)\end{array}$ & $\begin{array}{c}\text { Average } \\
\text { Dia. } \\
\mathrm{D}(\mathrm{mm})\end{array}$ & $\begin{array}{c}\text { Apparent } \\
\text { Density } \\
\left(\mathrm{g} / \mathrm{cm}^{3}\right)\end{array}$ & $\begin{array}{c}\text { Shell wall } \\
\text { thickness } \\
\mathrm{t}(\mu \mathrm{m})\end{array}$ & $\begin{array}{c}\text { Micro- } \\
\text { porosity } \\
(\%)\end{array}$ & $\begin{array}{c}\text { Adhesive } \\
(\%) \\
\text { mass }\end{array}$ & $t / R$ \\
\hline \hline SHS2 & 0.14 & 2.3 & 0.5 & $43-53$ & 10 & 15 & 0.04 \\
\hline SHS4 & 0.17 & 4.5 & 0.4 & $64-74$ & 12 & 13 & 0.03 \\
\hline
\end{tabular}

Table 1: Physical Properties of Steel Hollow Spheres

which was approximately $2.3 \mathrm{~mm}$ for the SHS2 and $4.5 \mathrm{~mm}$ for the SHS4. The shell walls of the metal foams are themselves porous, with microporosities of $10 \%$ and $12 \%$ for SHS2 and SHS4 respectively.

\subsection{Granular foam blocks}

The dimensions of the specimens are more than 10 diameters for both types, as dictated by the ISO standard for testing porous metals [10]. The production involved pouring hollow spheres coated with Araldite AT1-1 into square moulds with silicon linings. The spheres were poured in 3 stages, and compacted. Metal plates were used at the top and bottom to level the specimen, through which mild pressure was applied (Figure 2(b)). This was a necessary measure since absence of pressure leads to uneven surfaces and cavities within the specimen, since spheres shrink about $5 \%$ during curing. The curing was performed for 2 hours in an industrial oven at $160^{\circ} \mathrm{C}$. Once the specimen was removed from the oven, pressure was relieved and the specimen was allowed to cool down. Final dimensions and mass were recorded, as shown in Figure 2(d).

\section{Experimental work}

The experiments took place at the Structural Integrity lab of Cranfield University and the set up is shown in Figure 3. The tests were performed in monotonic compression or with one or two loading cycles at very slow displacement control on INSTRON servo-hydraulic testing rigs. The crosshead diplacement 


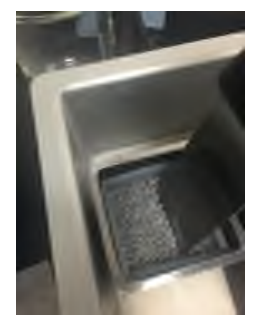

(a)

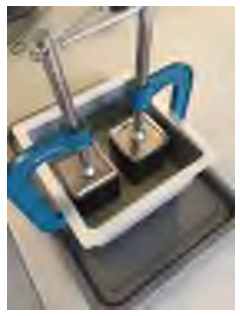

(b)

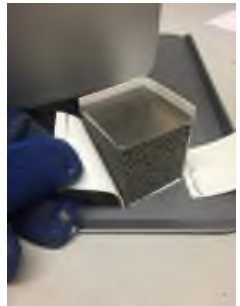

(c)

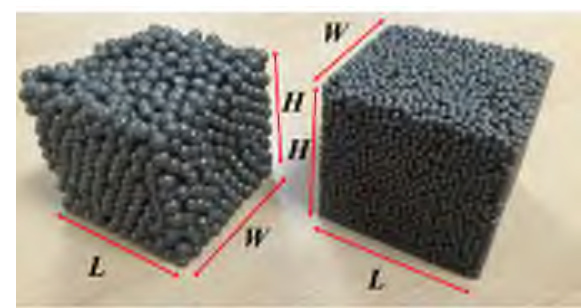

(d)

Figure 2: (a) Filling the mould in stages, (b) specimens ready for curing, (c) removing specimen during cooling down, and (d) indicating dimensions.

and load were recorded by the INSTRON console, while a DANTEC Q-400 Digital Image Correlation system (DIC) was used to capture surface deformations and strains. Digital Image correlation and photogrammetry techniques have been gaining traction recently in monitoring surface deformations for structural applications [11]. Heterogeneous materials such as metal foam assemblies, exhibit non-affine deformations and strain localizations, rendering their characterization based on single points insufficient. Several techniques for mapping strain fields in metal foams produced by hollow spheres, have been used [12, 7], but compared with micro-CT scans and other interferometric techniques for deformation measurement, 2-dimensional DIC offers a versatile and low requirement experimental set up which can reduce the testing costs. The tests were patterned after [10]. 7 specimens of each type were tested and their average physical properties and distributions are shown in Table 2. Experimental scheduling parameters are given in Table 3 . The specimen blocks were aligned face forward 
(height, $H \times$ length, $L$ ) and painted with a speckle pattern which is captured by DIC software and analysed using its algorithm to produce deformation and strain maps. At large deformations, DIC patterns breakdown and data is lost at crush bands as the experiment progresses. Nevertheless, useful deductions can be made.

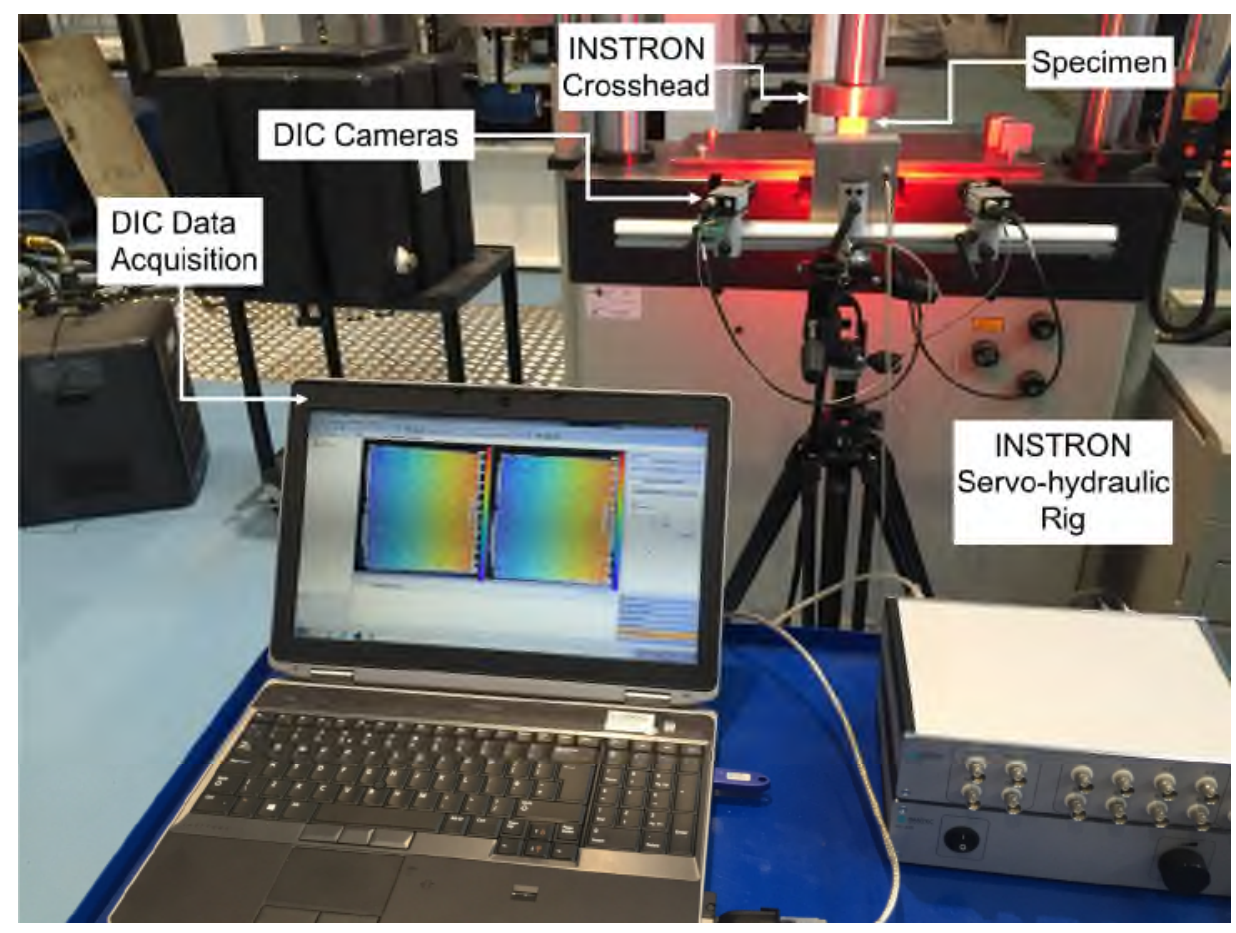

Figure 3: The experimental rig set up, indicating key components.

\begin{tabular}{|c|c|c|c|c|c|}
\hline Specimen & Mass $(\mathrm{g})$ & L $(\mathrm{mm})$ & $W(\mathrm{~mm})$ & $\mathrm{H}(\mathrm{mm})$ & $\begin{array}{c}\text { Density } \\
\left(\mathrm{g} / \mathrm{cm}^{3}\right)\end{array}$ \\
\hline SHS2 & $73.04 \pm 2.09$ & $50.3 \pm 0.2$ & $48.6 \pm 1.7$ & $50.2 \pm 0.9$ & $0.596 \pm 0.017$ \\
\hline SHS4 & $57.39 \pm 2.54$ & $50.3 \pm 0.6$ & $49.0 \pm 1.9$ & $50.5 \pm 0.3$ & $0.460 \pm 0.008$ \\
\hline
\end{tabular}

Table 2: Physical properties of the adhesively joined steel hollow sphere blocks. 


\begin{tabular}{|c|c|c|c|c|c|}
\hline Type & $\begin{array}{l}\text { Specimen } \\
\text { No. }\end{array}$ & $\begin{array}{l}\text { INSTRON } \\
\text { Loading } \\
\text { Rig }\end{array}$ & $\begin{array}{c}\text { Test } \\
\text { Method }\end{array}$ & $\begin{array}{l}\text { Loading } \\
\text { Rate } \\
(\mathrm{mm} / \mathrm{s})\end{array}$ & $\begin{array}{l}\text { DIC Acq. } \\
\text { Rate } \\
(\text { Frms } / \mathrm{s})\end{array}$ \\
\hline SHS2 & $\begin{array}{l}\text { I, VI, } \\
\text { VIII }\end{array}$ & $\begin{array}{c}8802 \\
(250 \mathrm{kN})\end{array}$ & $\begin{array}{c}\text { Compression with } \\
2 \text { loading/unloading } \\
\text { cycles }\end{array}$ & 0.2 & 5 \\
\hline SHS2 & $\begin{array}{l}\text { III, IV } \\
\text { V, VII }\end{array}$ & $\begin{array}{c}8803 \\
(500 \mathrm{kN})\end{array}$ & $\begin{array}{l}\text { Monotonic } \\
\text { compression }\end{array}$ & 0.2 & 4 \\
\hline SHS4 & II, III & $\begin{array}{c}8803 \\
(500 \mathrm{kN})\end{array}$ & $\begin{array}{l}\text { Monotonic } \\
\text { compression }\end{array}$ & 0.2 & 4 \\
\hline SHS4 & I & $\begin{array}{c}8803 \\
(500 \mathrm{kN})\end{array}$ & $\begin{array}{c}\text { Compression with } \\
1 \text { loading/unloading } \\
\text { cycle }\end{array}$ & 0.2 & 4 \\
\hline SHS4 & $\begin{array}{l}\text { IV, V, } \\
\text { VI, VII }\end{array}$ & $\begin{array}{c}8802 \\
(250 \mathrm{kN})\end{array}$ & $\begin{array}{l}\text { Compression with } \\
2 \text { loading/unloading } \\
\text { cycles }\end{array}$ & 0.2 & 5 \\
\hline
\end{tabular}

Table 3: Experimental procedure and parameters for each specimen

\section{Results and Discussion}

\subsection{Physical Properties of Hollow Steel Metal Foams}

The physical properties of the metal foam assemblies used, are summarized in Table 2. It is evident that our preparation protocol has produced highly reproducible specimens. The density of each specimen was determined independently, and was found as $0.59 \pm 0.01 \mathrm{~g} / \mathrm{cm}^{3}$ for SHS2 and $0.46 \pm 0.01 \mathrm{~g} / \mathrm{cm}^{3}$ for SHS4. These were converted to relative densities by dividing by the bulk density of steel, $\rho_{s}=7.87 \mathrm{~g} / \mathrm{cm}^{3}$, as $\frac{\rho}{\rho_{s}}=0.075 \pm 0.001$ for SHS2 and $\frac{\rho}{\rho_{s}}=0.058 \pm 0.001$ for SHS4.

The relative density of the steel foam unit cell may be given as: 


$$
\frac{\rho}{\rho_{s}}=P F\left[3\left(\frac{t}{R}\right)-3\left(\frac{t}{R}\right)^{2}+\left(\frac{t}{R}\right)^{3}\right] \frac{\left(1-\phi_{\text {micro }}\right)}{\left(1-m_{a d h}\right)}
$$

where, $R$ is the external radius of the spherical shell, $t$ is the thickness of the spherical shell, $P F$ is the packing factor or packing efficiency of the arrangement, that is the fraction of the unit cell volume occupied by spheres. We note that Eq.1 is similar to [13] adjusted for the microporosity, $\phi_{\text {micro }}=V_{\text {micro }} / V_{\text {shell }}$, where $V_{\text {micro }}$ is the volume of the spherical shell occupied by air voids and $V_{\text {shell }}$ is the volume of the spherical shell. Instead of using a volume fraction approach, the contribution of the adhesive in the overall density of the foam was accounted for though the adhesive mass fraction, $m_{a d h}$. The density of the foams was compared against the theoretical packing densities of hexagonal and square unit cells that exist in the literature. Based on this calculation, the packing achieved with our specimen preparation seems to be closer to a random packing (0.079 and 0.059 for SHS2 and SHS4 respectively), although locally spheres may be arranged in denser or looser packings.

\subsection{Stress-Strain Curves}

Typical stress-strain curves for SHS2 and SHS4 are shown in Figure 4, while important testing data are summarised in Table 3. The stress strain response of the specimens in this work exhibit the expected features of metal foams, which are described by three distinct regions. The first region, is the quasi-elastic region, where the stress is gradually increasing in a quasi-linear fashion leading to a first peak. The second region, begins with the first maximum compressive stress, and is defined by a plateau region, while large deformations occur. The third region is the densification region, marked by a stiffening behavior, as strength increases. A densified SHS4 specimen at the end of the loading is depicted in Figure 4.

\subsection{First maximum compressive strength}

The SHS2 had a mean first maximum compressive stress of $9.84 \mathrm{MPa}$, whereas the larger diameter SHS4 had a lower first maximum strength of 6.73 


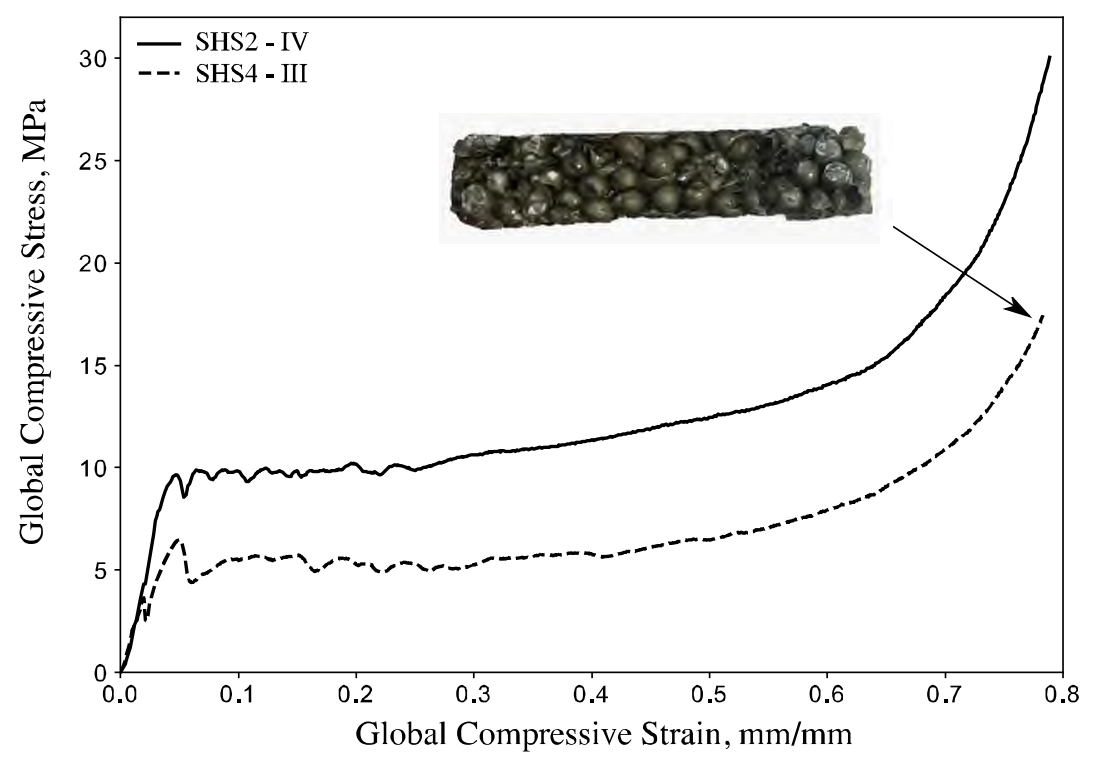

Figure 4: Typical stress-strain curves for SHS2 and SHS4 specimens. The figure also indicates an SHS4 specimen in a densified stage at the end of the experiment

$\mathrm{MPa}$, which amounts to about $32 \%$ difference. The standard deviation for both foams was in the order of 0.5 MPa. The difference in first compressive strength between the two foams can be attributed to the proportionality of the relative densities of the two foams.

\subsection{Plateau Stress}

The plateau stress, $\sigma_{p l}$, is calculated as the average of the stress values between 20\% and 30\% overall strain. The plateau stress for SHS2 was 10.02 MPa with a standard deviation of $0.35 \mathrm{MPa}$ and for the SHS4 5.83 MPa with a standard deviation of $0.43 \mathrm{MPa}$. The stress-strain curve for both SHS2 and SHS4 presents several undulations within the plateau region, which dissipate as the material enters the densification region. The undulations become smoother at a global strain level of approximately 0.25 for the SHS2 foam in contrast to the strain level of 0.45 for the SHS4. Furthermore, the undulations for SHS4 foams are comparatively deeper in comparison to the SHS2 ones. 


\begin{tabular}{|l|c|c|}
\hline & SHS2 & SHS4 \\
\hline \hline First Maximum Compressive Strength $(\mathrm{MPa})$ & $9.84 \pm 0.49$ & $6.73 \pm 0.35$ \\
\hline Plateau Stress $(\mathrm{MPa})$ & $10.02 \pm 0.35$ & $5.83 \pm 0.43$ \\
\hline Stress Drop Ratio (SDR) & $1.02 \pm 0.04$ & $0.86 \pm 0.06$ \\
\hline Plateau End Strain & $0.55 \pm 0.01$ & $0.56 \pm 0.06$ \\
\hline Energy Absorption at 50\% strain $\left(\mathrm{MJ} / \mathrm{m}^{3}\right)$ & $4.99 \pm 0.21$ & $2.83 \pm 0.10$ \\
\hline Energy Absorption Efficiency at $50 \%$ strain, $(\%)$ & $84.8 \pm 4.5$ & $87.3 \pm 3.9$ \\
\hline
\end{tabular}

Table 4: Summary of Results

\subsection{Stress Drop Ratio}

The stress Drop Ratio (SDR), is an important indicator of energy absorption of metal foams. Slightly different definitions of stress drop ratio exist, but herein we define it as the ratio between the first maximum compressive strength and the plateau stress such that $S D R=\sigma_{p l} / \sigma_{f m}$. We find that the stress drop ratio for SHS2 was 1.02 with a standard deviation 0.04, whereas for the SHS4 foams, the ratio was 0.86 with a standard deviation of 0.06 . The closer the SDR is to unity, the smoother the energy absorption transition is, which is important in automotive applications where impact injuries need to be avoided. In that respect the SHS2 seems to be a better energy absorber.

\subsection{Energy Absorption \& Energy Absorption Efficiency}

The energy absorption was calculated for each specimen by integrating numerically the stress-strain curve, up to the $50 \%$ strain level as:

$$
W=\int_{0}^{0.5} \sigma(\varepsilon) d \varepsilon
$$

The energy absorption for the SHS2 foams was found to be $4.99 \mathrm{MJ} / \mathrm{m}^{3}$ with a standard deviation of $0.21 \mathrm{MJ} / \mathrm{m}^{3}$ and for the SHS4 foams to be $2.83 \mathrm{MJ} / \mathrm{m}^{3}$ with a standard deviation of $0.1 \mathrm{MJ} / \mathrm{m}^{3}$. The energy absorption efficiency of each specimen was obtained by normalizing the energy absorption to the energy 
absorption of an ideal absorber at the stress corresponding to $50 \%$ strain. The ideal absorber in this case is one that absorbs energy at constant stress from 0 to $50 \%$ strain). The energy absorption efficiency of the two foams was found to be very similar, at $85 \%$ for the SHS 2 and $87 \%$ for the SHS4. Therefore the SHS2 absorbs more energy, while SHS4 exhibits a lower plateau stress which may be useful for protecting sensitive packages [14].

\section{Evolution of Displacement in granular foams}

Crush band formation is the predominant mechanism that governs the failure of metal foams. Digital image correlation is a useful tool that enables us to study and quantify the distribution of micro-scale deformation within a specimen as the loading schedule progresses. An understanding of the micro-scale phenomena will aid the optimization of the design of such complex materials for their intended purpose. Figure 5 highlights important and other failure events that occur at various strain levels within the plateau region for specimen SHS2V. Figure 6 presents the corresponding DIC heatmaps of total displacement, superimposed on the captured video images, and each subfigure corresponds to a point of interest. To aid the interpretation of results, the displacement contours are plotted on the heatmaps as well. The important features of the behavior of both types of foams are well captured in this specimen, thus we reserve from showing the results for the SHS4 foams. Contrast between the two foam types will be highlighted in the subsequent discussion.

Subfigure (a) shows the specimen pre-compression. Point (b) on the stressstrain curve is within the elastic range of the loading region. In the corresponding subfigure (b) we observe that the topmost layer of spheres already experiences increased localized displacements in comparison to the rest of the specimen. Furthermore, displacement contours of the topmost layer of spheres are on average horizontal, which indicates that the direction of compression of the top spheres is aligned with the global displacement direction. The displacement contours within the bulk of the specimen on the other hand, are diagonal 


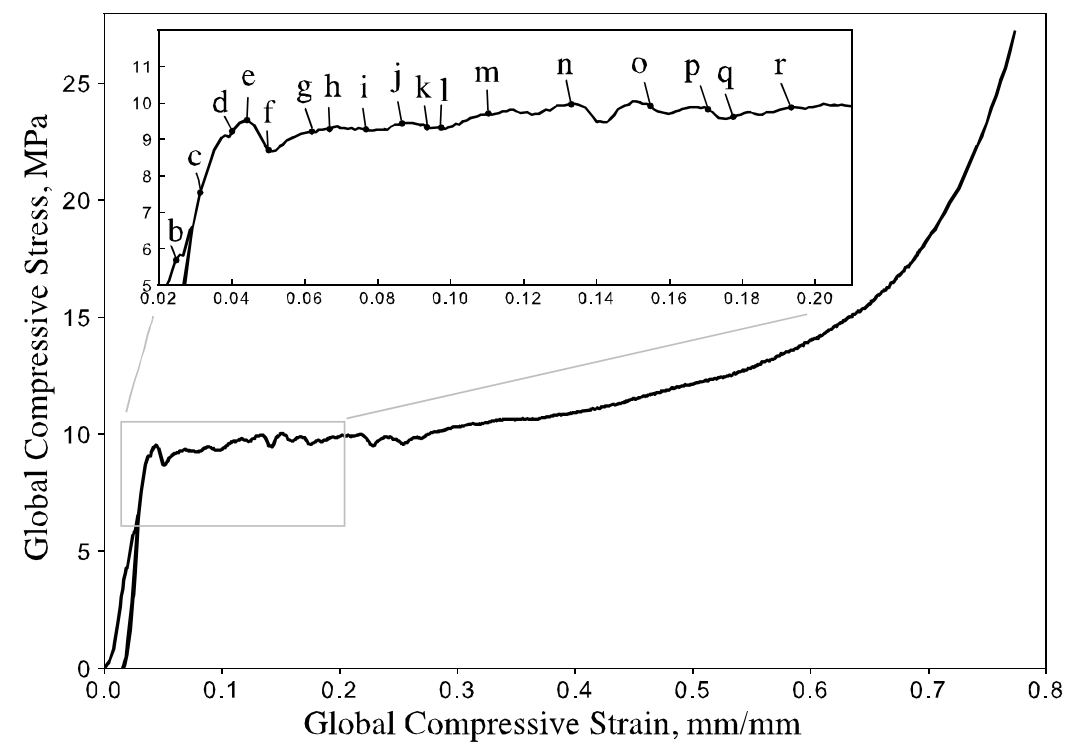

Figure 5: Detailed description of the crush bands events occuring in the plateau region of the SHS2-V specimen.

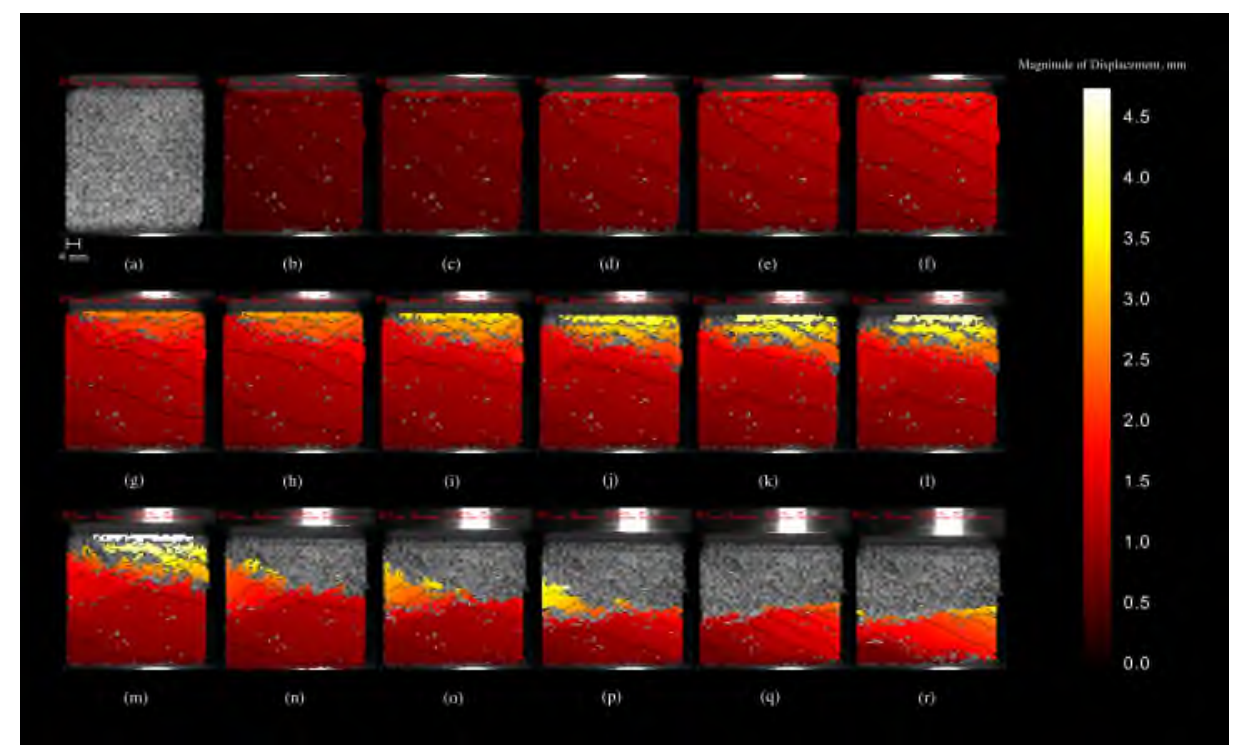

Figure 6: snapshot of the DIC contoured heat maps at the different events of interest indicated in Figure 5. 
indicating that the right part of the specimen is more compressed and that material locations are under normal and shear deformations.

A gradual softening, leading to the peak stress, is observed on the stressstrain curve beginning at point (c) and at a global strain of 0.031 . This softening behavior appears also in the SHS4 foam specimens. In the superimposed total displacement contour of subfigure (c), the deformation is slightly more concentrated at the topmost layer of spheres, adjacent to the loading plate. The compression of the topmost layer continues and the deformation becomes more prominent as the specimen compresses to point (d).

Point (e) signifies the first important landmark of the stress-strain curve, the first maximum compressive strength. At this load step, as shown by the increased values of the displacement contours of subfigure (e), the top layer crushes even further. Beyond the first peak, the load carrying capacity is reduced and the first dip in the stress/strain curve is observed at point (f). The first crush band event initiates and develops through points (g) and (h) at a global strain of $6.7 \%$. The localization event is evident in subfigure $(\mathrm{g})$ by the closeness of the contour lines, which indicates high displacement gradients. During this event crushed locations are observed within the top fourth of the specimen, and specifically between contour lines 2.5 and $2.25 \mathrm{~mm}$, the edge locations between the $2.25 \mathrm{~mm}$ and $2.0 \mathrm{~mm}$ lines, between the $2.0 \mathrm{~mm}$ and $1.75 \mathrm{~mm}$ lines and part of the $1.75 \mathrm{~mm}$ and $1.50 \mathrm{~mm}$ lines. During crushing, the DIC software loses track of some local regions due to excessive deformations, causing corruption of the speckled pattern. As a result, pixels corresponding to these local areas appear to contain no data. This is as indirect evidence of the formation of a crush band. At the same time, there is some deformation of the spheres adjacent to the bottom plate, not shown in the contour but captured in the video. Interestingly, the band shape of the collapsed zone is jagged as evidenced by the boundaries of the deformation zone and its width is approximately 2 diameters wide. Other authors have observed that these crush band zones occur in angles (30-40 deg), [15]. The crush bands are predominantly compressive although localized damage can lead to compressive-shear bands. Unlike honeycomb structures, hollow 
sphere assemblies do not have distinct layers normal to the axis of loading, hence weak zones can form in different angles to the direction of loading. In our case the crushing was predominantly compressive, although small shear slips were also observed.

The first crush band develops while the local resistance to crushing increases on a softer path and then plateaus after the first dip. This behavior, has also been observed in two-dimensional honeycombed structures [16] where the crashband development corresponds to a point on the stress strain curve where the stress increases (this indicates an increased resistance to crushing). We note that, in subfigure (h), during the initial crushing activity, a large part of the specimen remains relatively undeformed, as shown by the relatively large spacing of the $1.2 \mathrm{~mm}, 0.9 \mathrm{~mm}$ and 0.6 lines, while most of the deformation is concentrated in the area within the top plate and contour line $1.50 \mathrm{~mm}$. As the loading progresses, high displacement gradients are observed between the $2.8 \mathrm{~mm}$ contour line and $2.4 \mathrm{~mm}$ and 2.0 and $1.6 \mathrm{~mm}$ in subfigure (i), where at certain locations they seem to coalesce, signifying the formation of a secondary crush band caused by weakening of neighboring spheres. The same contour lines, come further apart from the localizations, indicating that there is less compressed material wedged between crush bands. Similarly, in subfigure (h), the left hand-side of contour line at $1.2 \mathrm{~mm}$, changes orientation and forms a wedged area with the $1.6 \mathrm{~mm}$ line. This wedged area is the beginning of a new crush band in the vicinity of the $1.2 \mathrm{~mm}$ line. The $1 \mathrm{~mm}$ contour line at the bottom half of the specimen in subfigures $(\mathrm{k})$ and $(\mathrm{l})$ is at a relatively small angle to the horizontal, and therefore the direction of compression of the spheres in the vicinity of the $1 \mathrm{~mm}$ line is aligned with the global motion of the crosshead.

So far, points (g) to (l) on the stress-strain curve are located on a local plateau which amounts to $3.5 \%$ of the global strain. Essentially, this $3.5 \%$ strain was used to deform the top third of the material, the rest of the material being essentially intact. At point $(\mathrm{m})$ on the stress stress strain curve, a marked gain in strength is noted which slighly surpasses the initial peak strength. The SHS2 specimens do not exhibit this behavior, and as the plateau stress always 
remains below the peak stress.

The wedged material to the left hand-side between lines $1.20 \mathrm{~mm} 2.00 \mathrm{~mm}$ compresses and presses upon the inclined plane marked by the line $1.20 \mathrm{~mm}$ which is apparently supported by an underlying stiffer organization of spheres, likely responsible for the increase in strength. For several load steps, up to a global strain of $13.3 \%$ the spheres surrounding the wedge in subfigure (n) keep on deforming, and in subfigure (o), the hollow spheres comprising its bottom boundary begin to crush as shown by the closeness of contours $2.40 \mathrm{~mm}, 2.00$ $\mathrm{mm}, 1.60 \mathrm{~mm}$ and $1.20 \mathrm{~mm}$. The dip between points (n) and (o) on the stressstrain curve marks this crushing event. We note once more that the material beneath contour line $1.2 \mathrm{~mm}$ is uniformly compressed. At point (p), the 1.00 $\mathrm{mm}$ contour line is inclined and material to the right of it is more compressed. This results in a clockwise rotation about the bottom right corner, which initiates a new diagonal crush-band, directed along the $1.00 \mathrm{~mm}$ line. The spheres contained between contour lines $1.25 \mathrm{~mm}, 1.00 \mathrm{~mm}$ and 0.75 and adjacent to the bottom plate, crush in subfigure (q) and which appears as a drop in strength in the stress-strain curve at point (q). In subfigure (r) the localization concentrates between contours $1.60 \mathrm{~mm}$ and $1.2 \mathrm{~mm}$ and partly between 1.2 and $0.8 \mathrm{~mm}$ as the bottom left corner of the specimen appears to be stiffer.

DIC data for subsequent load steps were not possible to be analyzed due to excessive deformations through the entire specimen. Two more crushing events occur during the rest of the plateau region, after which densification begins. During the test, no visible separation or cracking between spheres was observed up to $50 \%$ strain which suggests that there was no significant failure of the adhesive connecting the hollow spheres. The assembly seems to be able to keep the hollow spheres together after crushing. Thus, densified, stiffer zones remain integrated within the foam composite providing significant stability and increasing resistance to deformation. 


\subsection{Discussion of Results}

As discussed earlier, the first compressive strength peaks are consistent with the appearance of a localization band. Such strain localization bands are omnipresent and characteristic of microstured materials, such as metal foams, granular materials and laminates $[17,15,18,19]$. Althouth the mechanics of localization is still a matter of intense research, it is accepted that strain localizations, whether they manifest in the macro-scale as compaction, dilation, or shear bands, are a result of local mechanical instabilities [20, 21]. Molecular dynamics simulations of amorphous systems indicate triggering of local plastic events which resemble the elastic fields produced by Eshelby quadrupoles [22]. These local events occur as local rearrangements at the molecular level. Below the yield point these events are uncorrelated but once the yield point is exceeded, these Eshelby-like quadrupoles organize in lines or planes and form shear bands [23], while exhibiting a plastic flow plateau in their stress-strain behaviour [24].

From a granular micromechanics perspective, the material behaviour is determined by the grain-pair interactions and their orientation with respect to the loading direction. As a result, the macro-scale localization bands in granular materials and their fault angle, become not only a function of the macroscopic stress state but also of the macroscopic loading path [25, 26]. Although the metal foams presented herein bear similarities to cementitious granular materials, they are different in the fact that the microstructural building block is a spherical shell. Therefore, interpretation of our experimental findings in the context of micromechanics warrants complementary understanding of the behavior of spherical shells. As a point of departure, we contrast our results to the classical theory of shell buckling. The expression for the uniform pressure, $p_{c}$, at the onset of elastic buckling for a solid spherical shell was developed by Zoelly [27]:

$$
p_{c}=\frac{2 E}{\sqrt{3\left(1-\nu^{2}\right)}}\left(\frac{t}{R}\right)^{2}
$$

As indicated by Eq. 3 the onset of elastic buckling is governed by the Young's 
modulus, E and Poisson's ratio, $\nu$, and varies quadratically with the shell thickness to radius ratio (t/R), For the spheres used in this work, the smaller radius spheres will require approximately 1.86 times the pressure required for buckling than the larger spheres. This result is consistent with the 1.5 times increase of the first compressive strength observed between the SHS2 and SHS4 specimens. Of course the actual stress conditions on an individual hollow sphere are likely more complex and the contact conditions, their number and orientation need to be considered [28, 29, 30, 31].

The energy absorption of the SHS2 foams is approximately 1.76 times that of the SHS4 foams. As an integrated quantity, the energy absorption depends on the elastic gradient of the foam (region 1 of the stress-strain curve), the first compressive strength and the extent of the plateau region. The contribution of the adhesive to the behavior of the composite foam across the span of the stress-strain curve is a parameter that deserves some attention. Simulations by Fiedler et al [32] performed on adhesively bonded hollow sphere structures (partial HSS) showed that the elastic gradient affects largely the mechanical behavior and first peak of the metal foam. The softer the adhesive is, the softer is the elastic gradient of the metal foam before the first maximum. Also, stiffer adhesives result in higher first peaks up to a certain value of elastic gradient, beyond which the yield strength asymptotes to a constant. The adhesive menisci also mediate the force transfer at contact points and their geometry regulates the contact area over which the forces are applied.

Our findings suggest that the extent of the plateau region, depends upon the potential of sphere sub-assemblies to collapse and form crush bands, the number of which is not known a priori. The gradual collapse of crush bands is possibly attributed to the ability of the hollow sphere shells to form rolling plastic hinges [33].

\subsection{Comparison with Literature}

In this work, we focus on comparing data available for metal foams with a microstrucure similar to the foams reported herein. A summary of the quantities 
compared is provided in Table 5. In Figure 7, we plot the first maximum compressive strength as ordinate and the relative density of the each foam as the abscissa. On the same graph, shown as a solid like we plot, the expression $\sigma_{f m}=0.65 \sigma_{y}\left(\frac{\rho}{\rho_{s}}\right)^{1.36}$ from Sanders and Gibson [13], which predicts the first maximum compressive peak strength from relative density for metal hollow sphere foams, for yield strength of steel equal to $250 \mathrm{MPa}$. In general, we find that the first compressive strength of metal foams examined in this work is significantly higher than the sinterered metal foams reported in the literature. The higher first peak observed in our specimens is conjectured at this point to be due to the following reasons: (i) the adhesive distributes the forces between contacting hollow spheres over a larger contact area, and possibly delaying the onset of buckling for an individual sphere and (ii) the manufacturing protocol followed likely increases the number of contacts between spheres, and functions compositely with the adhesive to achieve a more uniform stress distribution over the spheres, increasing the buckling resistance. It is interesting to note that sintered hollow spheres exhibit consistently higher plateau stresses than the first maximum compression, regardless of the sphere size, something that we have observed only in the case of the SHS2. Confounding is the fact that for similar relative density, the first compressive peak varies more than 3 times. This reinforces the fact that relative density alone is not a good predictor of mechanical properties and the microstructural aspects needs to be considered for property prediction of heterogeneous materials.

\section{Conclusions}

Compression tests and Digital Image Correlation techniques have been applied to measure the compressive strength and quantify the deformations that occur within adhesively bonded steel hollow sphere assemblies. The first peak strength for assemblies of both sphere sizes seem to be higher than similar assemblies of sintered sphere assemblies. The random packing of the spheres in the assembly leads to weak zones where the material fails by forming crush bands as 


\begin{tabular}{|c|c|c|c|c|c|c|c|}
\hline & \multicolumn{2}{|c|}{$\begin{array}{c}\text { This } \\
\text { work }\end{array}$} & \multicolumn{2}{c|}{$\begin{array}{c}\text { Gao et al. } \\
2008 \text { (Sintered) }\end{array}$} & \multicolumn{2}{|c|}{$\begin{array}{c}\text { Friedl et al. } \\
2007 \text { (Sintered) }\end{array}$} & $\begin{array}{c}\text { Szyniszewski } \\
\text { et al 2014 } \\
\text { (Sintered) }\end{array}$ \\
\hline $\begin{array}{c}\text { Spheres } \\
\varnothing(\mathrm{mm})\end{array}$ & 4.5 & 2.3 & 3 & 1.8 & 4 & 2 & 2 \\
\hline$t / R$ & 0.030 & 0.042 & 0.032 & 0.054 & 0.047 & 0.035 & 0.086 \\
\hline $\begin{array}{c}\text { First max. } \\
\text { compressive } \\
\text { strength (MPa) }\end{array}$ & 6.73 & 9.84 & 3.06 & 2.10 & 3.05 & 1.27 & 4 \\
\hline $\begin{array}{c}\text { Plateau } \\
\text { Stress (MPa) }\end{array}$ & 5.83 & 10.02 & 3.66 & 2.91 & 3.93 & 1.49 & $\begin{array}{c}0.01 \text { proof } \\
\text { stress) }\end{array}$ \\
\hline$\rho / \rho_{s}$ & 0.058 & 0.075 & 0.052 & 0.044 & 0.08 & 0.04 & 0.145 \\
\hline
\end{tabular}

Table 5: Comparison with data from the literature.

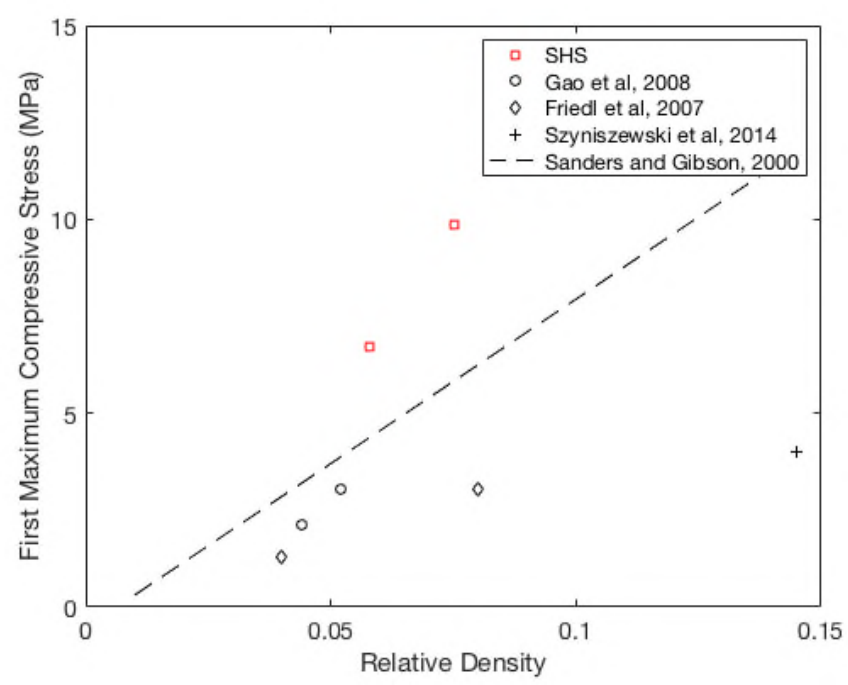

Figure 7: First maximum compressive stregth vs Relative Density for the data in Table 5. The dashed line represents the result by Sanders and Gibson[13] using yield strength of steel equal to $250 \mathrm{MPa}$ 
the compressive strain increases, while material between crush bands exhibits very little deformation. The response is driven by an average stress plateau comprising successive crush band events which have been clearly highlighted, with reproducible results between specimens. Furthermore it was found that SHS2 absorbs almost double $(\times 1.76)$ energy than the SHS4, mainly due to the higher plateau stress. Our results suggest that epoxy bonded granular metal foams provide a promising alternative to existing assembly methods for hollow spheres. The methodology produces, a range of macroscale material properties by modifying the microstructural unit size. The span of properties, their relationship to the microstucture and the range of applications of this material will be investigated in future studies.

\section{Acknowledgments}

SY and FPB have received funding from the European Union's Seventh Framework Programme for research, technological development and demonstration under grant agreement no 623874. More information can be found on www.insist-eu.weebly.com. The authors would also like to acknowledge the support of Hollomet GmbH which provided metallography results of the hollow spheres.

\section{References}

[1] B. Smith, S. Szyniszewski, J. Hajjar, B. Schafer, S. Arwade, Steel foam for structures: A review of applications, manufacturing and material properties, Journal of Constructional Steel Research 71 (2012) 1-10.

[2] J. Banhart, Manufacture, characterisation and application of cellular metals and metal foams, Progress in materials science 46 (6) (2001) 559-632.

[3] K. Boomsma, D. Poulikakos, Y. Ventikos, Simulations of flow through open cell metal foams using an idealized periodic cell structure, International Journal of Heat and Fluid Flow 24 (6) (2003) 825-834. 
[4] H. Goehler, U. Jehring, J. Meinert, R. Hauser, P. Quadbeck, K. Kuemmel, G. Stephani, B. Kieback, Functionalized Metallic Hollow Sphere Structures: Functionalized Metallic Hollow Sphere Structures, Advanced Engineering Materials 16 (3) (2014) 335-339. doi:10.1002/adem.201300057.

URL http://doi.wiley.com/10.1002/adem. 201300057

[5] P. Lhuissier, A. Fallet, L. Salvo, Y. Brechet, Quasistatic mechanical behaviour of stainless steel hollow sphere foam: Macroscopic properties and damage mechanisms followed by X-ray tomography, Materials Letters 63 (13-14) (2009) 1113-1116. doi:10.1016/j.matlet.2008.10.051.

URL http://linkinghub.elsevier.com/retrieve/pii/ S0167577X08008896

[6] A. Rabiei, L. Vendra, A comparison of composite metal foam's properties and other comparable metal foams, Materials Letters 63 (5) (2009) 533536. doi:10.1016/j.matlet.2008.11.002.

[7] Z. Y. Gao, T. X. Yu, H. Zhao, Mechanical behavior of metalic hollow sphere materials: Experimental study, Journal of Aerospace Engineering 21 (4) (2008) 206-216.

[8] O. Friedl, C. Motz, H. Peterlik, S. Puchegger, N. Reger, R. Pippan, Experimental Investigation of Mechanical Properties of Metallic Hollow Sphere Structures, Metallurgical and Materials Transactions B 39 (1). doi : $10.1007 /$ s11663-007-9098-2.

[9] S. Szyniszewski, B. Smith, J. Hajjar, B. Schafer, S. Arwade, The mechanical properties and modeling of a sintered hollow sphere steel foam, Materials \& Design (1980-2015) 54 (2014) 1083-1094.

[10] ISO, Iso 13314: Mechanical testing of metals-ductility testing-compression test for porous and cellular metals, Tech. rep., ISO (2011).

[11] D. Skarlatos, S. Yiatros, Deformation monitoring of materials under stress 
in laboratory experiments, ISPRS Annals of the Photogrammetry, Remote Sensing and Spatial Information Sciences 3 (2016) 35.

[12] M. Vesenjak, M. Borovinšek, T. Fiedler, Y. Higa, Z. Ren, Structural characterisation of advanced pore morphology (apm) foam elements, Materials letters 110 (2013) 201-203.

[13] W. S. Sanders, L. J. Gibson, Mechanics of hollow sphere foams, Materials Science and Engineering: A 347 (1) (2003) 70-85. doi:https://doi.org/ 10.1016/S0921-5093(02)00583-X.

[14] M. F. Ashby, A. G. Evans, N. A. Fleck, L. J. Gibson, J. W. Hutchinson, H. N. G. Wadley, Metal foams: a design guide., Butterworth-Heinemann, 2000 .

[15] T. Fiedler, A. Öchsner, Elastic-plastic properties: Simulation and experiment, in: A. Öchsner, C. Augustin (Eds.), Multifunctional Metallic Hollow Sphere Structures, Springer, 2009, pp. 47-70.

[16] S. D. Papka, S. Kyriakides, In-plane crushing of a polycarbonate honeycomb, International Journal of Solids and Structures 35 (3) (1998) 239-267. doi:https://doi.org/10.1016/S0020-7683(97)00062-0.

[17] S. Forest, J.-S. Blazy, Y. Chastel, F. Moussy, Continuum modeling of strain localization phenomena in metallic foams, Journal of Materials Science 40 (22) (2005) 5903-5910. doi:10.1007/s10853-005-5041-6.

[18] Y. Yang, A. Misra, Higher-Order Stress-Strain Theory for Damage Modeling Implemented in an Element-free Galerkin Formulation, CMESCOMPUTER MODELING IN ENGINEERING \& SCIENCES 64 (1) (2010) 1-36.

[19] M. A. Wadee, C. Völlmecke, J. F. Haley, S. Yiatros, Geometric modelling of kink banding in laminated structures, Philosophical Transactions of the Royal Society A 370 (1965) (2012) 1827-1849. doi:10.1098/rsta.2011. 0380 . 
[20] P. Bésuelle, J. Rudnicki, Chapter 5 localization: Shear bands and compaction bands, International Geophysics 89 (C) (2003) 219-321. doi: 10.1016/S0074-6142(03)80021-9.

[21] A. Misra, P. Poorsolhjouy, Micro-macro scale instability in 2d regular granular assemblies, Continuum Mechanics and Thermodynamics 27 (1-2) (2015) 63-82.

[22] G. Parisi, I. Procaccia, C. Rainone, M. Singh, Shear bands as manifestation of a criticality in yielding amorphous solids, Proceedings of the National Academy of Sciences 114 (22) (2017) 5577-5582.

[23] R. Dasgupta, H. G. E. Hentschel, I. Procaccia, Yield strain in shear banding amorphous solids, Physical Review E 87 (2) (2013) 022810.

[24] A. Le Bouil, A. Amon, J.-C. Sangleboeuf, H. Orain, P. Bésuelle, G. Viggiani, P. Chasle, J. Crassous, A biaxial apparatus for the study of heterogeneous and intermittent strains in granular materials, Granular Matter 16 (1) (2014) 1-8.

[25] B. Haimson, J. W. Rudnicki, The effect of the intermediate principal stress on fault formation and fault angle in siltstone, Journal of Structural Geology 32 (11) (2010) 1701-1711.

[26] P. Poorsolhjouy, A. Misra, Effect of intermediate principal stress and loading-path on failure of cementitious materials using granular micromechanics, International Journal of Solids and Structures 108 (2017) 139-152.

[27] S. P. Timoshenko, J. M. Gere, Theory of elastic stability, 1st Edition, New York : McGraw-Hill, 1961.

[28] A. Misra, C. S. Chang, Effective elastic moduli of heterogeneous granular solids, International Journal of Solids and Structures 30 (18) (1993) 2547-2566. doi:https ://doi .org/10 . 1016/0020-7683(93)90165-4.

URL http://www.sciencedirect.com/science/article/pii/ 0020768393901654 
[29] A. Misra, O. Marangos, Rock-joint micromechanics: relationship of roughness to closure and wave propagation, International Journal of Geomechanics 11 (6) (2010) 431-439.

[30] H. Ruan, Z. Y. Gao, T. Yu, Crushing of thin-walled spheres and sphere arrays, International Journal of Mechanical Sciences 48 (2) (2006) 117 133, 7th Asia-Pacific Symposium on Advances in Engineering Plasticity and its Applications (AEPA 2004). doi:https://doi.org/10.1016/j. ijmecsci.2005.08.006.

[31] M. Shariati, H. R. Allahbakhsh, Numerical and experimental investigations on the buckling of steel semi-spherical shells under various loadings, ThinWalled Structures 48 (8) (2010) 620-628. doi :https://doi.org/10.1016/ j.tws. 2010.03 .002 .

[32] T. Fiedler, A. Öchsner, J. Grácio, Numerical investigations on the mechanical properties of adhesively bonded hollow sphere structures, Journal of Composite Materials 44 (10) (2010) 1165-1178. doi:10.1177/ 0021998309348409.

URL https://doi.org/10.1177/0021998309348409

[33] P. K. Gupta, N. K. Gupta, A study of different modes of collapse in metallic hemispherical shells resting on flat platen and compressed with hemispherical nosed indenter, International Journal of Solids and Structures 51 (13) (2014) 2518-2528. doi:https://doi.org/10.1016/j.ijsolstr. 2014.03 .023$. 